Topiques, études satoriennes

Topoï Studies, Journal of the SATOR

\title{
L'échec du mentorat dans Les malheurs de l'amour (1747) de Madame de Tencin et dans Les Lettres du marquis de Roselle (1764) de Madame Élie de Beaumont
}

\section{Sante Arcangelo Viselli}

Volume 4, 2018

Maître-disciple : une relation topique

URI : https://id.erudit.org/iderudit/1074721ar

DOI : https://doi.org/10.7202/1074721ar

\section{Aller au sommaire du numéro}

\section{Éditeur(s)}

SATOR, Société d'Analyse de la Topique Romanesque d'Ancien Régime

\section{ISSN}

2369-4831 (numérique)

\section{Découvrir la revue}

\section{Citer cet article}

Viselli, S. (2018). L'échec du mentorat dans Les malheurs de l'amour (1747) de Madame de Tencin et dans Les Lettres du marquis de Roselle (1764) de

Madame Élie de Beaumont. Topiques, études satoriennes / Topoï Studies, Journal of the SATOR, 4, 1-26. https://doi.org/10.7202/1074721ar

\section{Résumé de l'article}

Le roman du siècle des Lumières est riche en topoi mettant en scène le mentor : Madame de Tencin dans Les Malheurs de l'amour (1747) et Madame Élie de Beaumont dans les Lettres du marquis de Roselle (1764) sont particulièrement sensibles à la mise en scène de ce personnage qui évolue depuis Fénelon de manière dramatique. Dans les textes étudiés, ce conseiller avisé, souvent une femme, évoque une philosophie qui dépasse son symbolisme classique : souvent maître à penser, il devient lui-même un porte-parole désabusé des Lumières, mais il en sera lui-même/elle-même victime. Il/elle guide le mentoré/la mentorée à travers la forêt obscure des illusions passionnelles, celles de l'amour certes, mais celles engendrées surtout par le jeu quelque peu contradictoire des intérêts de classe, de la morale bourgeoise en mal de devenir et d'une aristocratie appauvrie, décadente et libertine.

Le XVIIIe siècle voit une véritable métamorphose du mentor classique : il continue de remplir le rôle pluriel de conseiller, mais aussi de modèle d'ordre narratologique surtout chez Madame de Tencin -la référence obligée demeurant Madame de Lafayette. Davantage, le mentor devient au siècle des Lumières un être en chair et en os, sensuel et passionné et dont la morale atteint plutôt une dimension anthropologique, qui ausculte les lois et les sonde à la lumière de la raison. Le siècle des « libertins " est le siècle d'un mentorat repensé, calculé, teinté souvent de ce mal existentiel, résurgence des forces du « moi » double qui caractérise l'être, une philosophie inaugurée par Montaigne et qui trouvera ses échos chez Descartes ou Pascal entre autres. Ce mal persiste au siècle de la " raison " malgré l'optimisme qui semble le caractériser. Nous limitons notre analyse aux deux romans mentionnés dans l'intitulé, mais il serait souhaitable, dans des études ultérieures et pour enrichir la base des données de la SATOR, d'élargir le débat à d'autres romans des Lumières. 
Sante Viselli

\section{L'échec du mentorat dans Les malheurs de l'amour (1747) de Madame de Tencin et dans Les Lettres du marquis de Roselle (1764) de Madame Élie de Beaumont}

Rappelons avant tout que le roman du siècle des Lumières est particulièrement riche en topoi mettant en scène le mentor dont la plurivocité risque parfois de compromettre l'interprétation classique : Madame de Tencin et Madame Élie de Beaumont n'échappent pas à cet attrait sublimé d'un personnage qui, dans un premier temps, pourrait apparaître trop parfait pour être vrai. Le mentor incarne en principe ce conseiller avisé et expérimenté que le héros/l'héroïne de roman trouve sur son chemin existentiel, un personnage allégorique, manifestation matérielle du maître à penser et porte-parole de la raison des Lumières. Cependant, dans un siècle qui à force de se vouloir philosophe ne semble pas l'être assez, ce maître idéal se colore d'ambigüité onomasiologique : il/elle guide le mentoré/la mentorée à travers la forêt obscure des illusions passionnelles, celles engendrées surtout par le jeu quelque peu contradictoire des intérêts de classe, de la morale bourgeoise en butte aux convoitises, à l'envie, à l'humiliation de la classe aristocratique et décadente, ou de l'amour tout court et ses contradictions stéréotypées. Le nouveau mentor du XVIII ${ }^{\mathrm{e}}$ siècle s'éloigne de la tradition classique, celle réactualisée par exemple par Fénelon (référence obligée, Télémaque, publié en 1699 en pleine «crise de conscience européenne » selon le mot bien connu de Paul Hazard), et se définit plutôt par une rhétorique plus particulière et plus conforme aux idées véhiculées par le siècle des Lumières. En fait, au XVIII siècle, l'on assiste à une véritable métamorphose de ce personnage dont la trace se confond avec l'Antiquité, avec la Bible, Homère et Virgile, et qui remplit le rôle pluriel de conseiller à la fois d'ordre philosophique et moral, mais aussi d'inspirateur d'ordre narratologique surtout chez les auteurs dont il est question dans cette analyse. Le mentor, qui dans l'Antiquité se confondait avec la divinité, ne cesse tout de même d'être un personnage allégorique : davantage, il devient au siècle des Lumières un être en chair et en os, sensuel et passionné et dont la morale a plutôt une 
dimension anthropologique, qui ausculte les lois et les sonde à la lumière de la raison, de l'histoire, de la politique, de la tradition, de la morale et de l'économie. Le siècle des « libertins » est le siècle d'un mentorat repensé, calculé, teinté souvent de ce mal existentiel, résurgences des forces du « moi » double qui caractérise l'être, une philosophie inaugurée par Montaigne et qui trouvera ses échos chez Descartes ou Pascal entre autres. Ce mal persiste au siècle des Lumières malgré l'optimisme qu'elles semblent préconiser. Nous limitons notre analyse aux deux romans mentionnés dans l'intitulé, mais il serait souhaitable, dans des études ultérieures et pour enrichir la base des données de la SATOR, d'élargir le débat à d'autres textes ${ }^{1}$.

Le roman de Madame de Tencin (Les Malheurs de l'amour, 1747) est assez bien connu, surtout depuis la réédition d'Erik Leborgne chez Desjonquères (2001). L'isotopie centrale de cette fiction romanesque semble répondre aux souhaits des organisateurs du colloque international tenu à Melbourne en 2016 et elle s'organise justement autour des rapports mentormentoré dans la littérature d'Ancien Régime. Avançons déjà que chez Madame de Tencin le lecteur ressent l'échec du mentorat dans le sens classique du terme - c'est le cas de la plupart des fictions romanesques du XVIII ${ }^{\mathrm{e}}$ siècle - donc de sa raison suffisante versus la valorisation du cœur, une image paradoxalement pascalienne, mais que Montesquieu, par exemple, n'hésitera pas à qualifier si poétiquement de « citoyen de tous les pays $»^{2}$, et que Marivaux a tant magnifié dans ses œuvres - rappelons que ces deux écrivains étaient amis intimes de Madame de Tencin. Cependant, si la raison, qui semble être la conditio sine qua non du mentor, échoue chez Madame de Tencin, elle triomphera dans le roman de Madame Élie de Beaumont, Les Lettres du marquis de Roselle, dont il sera question plus tard. Notons que, dans ce roman, le jeune marquis pris dans les filets de son mentor, le libertin Valville, sera récupéré in extremis grâce aux efforts d'autres guides, porte-parole de la tradition aristocratique à tendance moralisatrice et immuable, en antithèse avec le mouvement philosophique préconisé par le libertinage du XVIII ${ }^{\mathrm{e}}$ siècle, celui-ci étant fondé plutôt sur la libération de l'être de toutes ses contraintes, une philosophie d'ailleurs ancrée dans les lois physiques du mouvement et, par conséquent, dans celles de l'inconstance des

\footnotetext{
${ }^{1}$ Nous en avons reproduit quelques exemples à la fin de la présente étude (Annexe 2).

${ }^{2}$ Montesquieu, « Lettre LXVII », Lettres persanes, 1973, p. 169.
} 
êtres, du caprice des passions et sentiments humains ${ }^{3}$. Contrairement au roman de Madame de Tencin, la vertu, l'amour et le bonheur finiront par triompher au dénouement de celui de Madame Élie de Beaumont, chose qui arrive rarement dans les romans du XVIII ${ }^{\mathrm{e}}$ siècle.

La fiction romanesque de Madame de Tencin met en scène les péripéties de trois femmes de condition sociale différente : Pauline, Hippolyte et Eugénie. La narratrice, Pauline, segmente le texte en récits événementiels et retrace les étapes dramatiques de sa vie depuis son séjour au couvent où elle rencontre Eugénie, personnage énigmatique mais stable, qui la prendra sous sa tutelle jusqu'à sa retraite finale, dans la solitude de son château à l'écart du monde. L'histoire d'amour de Pauline commence par la rencontre de Barbasan, jeune aristocrate qui se distingue considérablement des autres jeunes nobles, oisifs et prétentieux, assidus alors de sa maison, Barbasan qu'elle ne peut épouser à cause des machinations ourdies par leurs ennemis communs (c'est le topos des amours contrariées) et par sa condition de jeune noble d'ascendance obscure et appauvri. Mis en prison pour avoir tué en duel son rival, il est condamné à mourir sur l'échafaud. Pauline réussit à le faire évader et se résout, malgré les conseils de son mentor Eugénie, à le rejoindre à l'étranger. Mystification romanesque oblige, pendant la fuite, le prétendu jeune homme qui l'accompagnait se révèle être une jolie femme, (autre topos bien repéré dans les romans de Madame de Tencin, celui du travestissement de la femme en homme), Hippolyte fille du geôlier gagné à la cause de Barbasan et qui aide ce dernier à s'échapper. La naissance d'un enfant sera le fruit de leur courte et malheureuse liaison. Trompée par la situation compromettante dans laquelle Pauline trouve le couple, manifestement marquée par la culpabilité de son ancien amant, elle rentre en France et, suite aux conseils d'Eugénie, elle épousera Monsieur d'Hacqueville, homme digne et respectable que la jeune héroïne estime mais n'aime pas, un rappel plus que significatif de l'œuvre de Madame de la Fayette, véritable mentor symbolique et modèle intellectuel et littéraire que Madame de Tencin n'hésite pas à imiter dans toutes ses fictions romanesques ${ }^{4}$. Le modèle l'exige, le mari jaloux se croyant trompé mourra de chagrin (autre topos du triangle fatal bien connu). Pauline choisira la retraite. Pendant une promenade près de son château, attaquée par son vieil ennemi, le marquis de N...., noble

\footnotetext{
${ }^{3}$ Rappel éloquent de Dom Juan de Molière (Acte I, scène 2) : «La belle chose de vouloir se piquer d'un faux honneur d'être fidèle, de s'ensevelir pour toujours dans une passion, et d'être mort dès sa jeunesse, à toutes les autres beautés qui nous peuvent frapper les yeux ! Non, non : la constance n'est bonne que pour les ridicules ; [...] et tout le plaisir de l'amour est dans le changement. " (Molière, Dom Juan, Paris, 1998, p. 42)

${ }^{4}$ Andrea Turekova, "Les 'sœurs' de la Princesse de Clèves au XVIII' siècle : exemple des héroïnes de madame de Tencin », 2013, p. 73-82.
} 
dépravé, responsable de sa déchéance et de celle de Barbasan, elle sera sauvée par son ancien amant. Cependant, Barbasan sera mortellement blessé. Trop tard, Pauline comprendra sur quels malentendus était fondée sa vie amoureuse : elle aurait irrémédiablement tout perdu. Elle n'aurait défendu que des tombeaux, car Barbasan n'avait jamais cessé de l'aimer. Le bonheur étant irrémédiablement compromis, les personnages de ce roman sont emportés au dénouement par le vertige de la mort, à l'exception près de l'orphelin, fils de Barbasan et d'Hippolyte, que Pauline sauvera de l'indigence et probablement de la mort. Pauline sera son appui, sa bienfaitrice ; lui, il sera le fils qu'elle n'a jamais eu, un rappel de son ancien amant, de son destin tragique. L'œuvre de ce mentor exemplaire s'accomplira cependant à l'ombre de l'anonymat :

La fortune de ce malheureux enfant est la seule chose qui a pu faire quelque distraction à ma douleur, dit la narratrice. Je l'ai mis de bonne heure dans les troupes; il y jouit d'une réputation brillante. Il est actuellement dans les premiers grades. J'ai cru devoir lui laisser toujours ignorer ce qu'il est. Il ne sait pas même d'où lui vient le bien qu'il reçoit : j'ai mieux aimé renoncer à sa reconnaissance que de lui donner la mortification de se connaître. ${ }^{5}$

L'histoire de Pauline commence au couvent: la jeune fille de quatorze ans, gâtée par ses parents et trompée par les prétentions sociales que sa mère attache aux titres de noblesse, rencontre Eugénie - celle-ci deviendra son mentor - qui la console, lui donne des conseils, la guide dans le dur apprentissage de la réalité et lui apprend à percer les masques sur lesquels se fonde une société en général hypocrite et trop habituée à paraître. C'est ainsi que s'exprime la narratrice après avoir subi les affronts de Mademoiselle de Renonville, jeune fille de souche noble et que sa naissance place, au sein de la pyramide sociale de l'Ancien Régime, au-dessus de Pauline - rappelons que celle-ci est très riche, mais bourgeoise :

Une religieuse plus raisonnable que les autres, et véritablement raisonnable, vint me tirer de cette embarrassante situation, et m'emmena dans sa chambre.

Dès que nous y fûmes, je me mis à pleurer de tout mon cœur. [...] Eugénie (c'était le nom de la religieuse) n'attendit pas mes questions : vous avez le cœur bon, me dit-elle, et je vous crois l'esprit assez avancé, pour être capable de comprendre ce que j'ai à vous dire. On ne vous a mis jusqu'ici que des idées fausses dans la tête, et il faudra vous en défaire. ${ }^{6}$

Le discours de la maîtresse qui dirige sa pupille se trouve réactualisé dans ces mémoires que Pauline rédige probablement à un âge mûr, donc avec la sagesse et le recul qu'impose l'écoulement du temps. La narratrice connaît déjà, au moment où elle rédige son récit, l'histoire d'Eugénie, ses péripéties et ses déboires. Cependant, le lecteur/la lectrice est dans l'attente du

${ }^{5}$ Claudine-Alexandrine Guérin de Tencin, Les Malheurs de l'amour, 2001, p. 149.

${ }^{6}$ Idem, p. 39. 
devenir, dans le suspense de l'incertain qui englobe la jeune destinée de Pauline et qu'Eugénie devra diriger afin qu'elle ne s'écrase pas sur les écueils de la manipulation, de la décadence morale et des rêves de «bourgeois gentilhomme » qui hantaient alors la bourgeoisie en France. La narratrice évoque de manière désenchantée cette vie passée où tout était moquerie, fauxsemblant, trompe-l'œil. En fait, les nobles ne fréquentaient sa maison que pour y faire bonne chère, ou encore dans la perspective d'y contracter un riche mariage. A posteriori, Pauline ne peut s'empêcher de penser sans ironie que ces nobles ne venaient chez elle que pour « le plaisir de se moquer de nous [...] $»^{7}$. L'hypocrisie semble être donc ce vice à la mode de la noblesse décadente, certes un rappel assez sonore du Dom Juan de Molière ${ }^{8}$, et le discours qu'Eugénie adresse à sa protégée masque mal la tempête qui s'annonce déjà sur cette mer houleuse de la société française où seule la boussole de la raison aurait pu ramener les êtres et leurs actions à la sagesse, à leur juste dimension humaine. Mais la raison invoquée par ce mentor ambigu qu'est Eugénie n'est pas celle de Pauline: Eugénie est porte-parole, malgré tout, d'une morale aristocratique fondée sur l'orgueil, l'amour-propre et la fierté, donc sur un concept de l'honneur qui se rattache plus à une vertu farouche à la Romaine - rappel sans doute de Corneille - qu'à la charité chrétienne qu'elle semble pratiquer au couvent. Eugénie est un personnage sibyllin, elle ne se réconciliera jamais avec le monde et ne donnera jamais à son amant, La Valette qu'elle aime pourtant, la possibilité de la retirer du gouffre intérieur dans lequel elle est plongée et de lui faire remonter la pente du désespoir et de l'angoisse de ne pas être ce qu'elle aurait souhaité être. Personnage anti-prométhéen, porte-parole d'une morale à sens unique qui prêche le conformisme et le statu quo, elle développe un rapport transactionnel avec le monde. Le monde étant ce qu'il est, il est inutile et même déraisonnable de se battre pour un bonheur qui, en tout cas, ne se concrétisera jamais. Tel Sisyphe, il vaudra mieux se conformer à son existence et subir le désespoir. Plus Martin que Pangloss, désabusée, Eugénie dirige sa mentorée vers le port de l'indifférence, seul abri au malheur inévitable auquel Pauline se voue désormais depuis qu'elle écoute, selon Eugénie, la voix du cœur.

\footnotetext{
${ }^{7}$ Idem, p. 42-45.

${ }^{8}$ Dom Juan : «Il n'y a plus de honte maintenant à cela : l'hypocrisie est un vice à la mode, et toujours les vices à la mode passent pour vertus. Le personnage d'homme de bien est le meilleur de tous les personnages qu'on puisse jouer aujourd'hui, et la profession d'hypocrite a de merveilleux avantages. C'est un art de qui l'imposture est toujours respectée ; et quoiqu'on la découvre, on n'ose rien dire contre elle. » (Molière, Dom Juan, Acte V, scène 2, op. cit., p. 141)
} 
L'univers d'attente topique de l'époque prépare le lecteur à la suite du roman: Pauline écoute son guide, mais ne cessera cependant de suivre l'inclination de son cœur, elle en sera la dupe, ne serait-ce que pendant un certain temps, mais, tout compte fait, elle restera fidèle, particulièrement dans le malheur, à son idéal de pureté, d'honnêteté conforme à son sens de la vertu : c'est l'assurance qui lui vient du cœur, ce troisième œil, source d'une connaissance qui transcende bien sa réalité, ou celle d'Eugénie, une réalité d'ailleurs fondée sur l'éphémère des prétentions humaines. « Le cœur a ses raisons que la raison ne connaît point ${ }^{9}$, dit Pascal, mais cette pensée, devenue désormais un lieu commun de la littérature amoureuse, semble caractériser la jeune amante, même dans le plus profond de son désespoir. Eugénie s'ensevelit dans un cloître pour se punir de sa déchéance physique et morale. Certes avec courage, elle réussit à dépasser sa crise émotive, mais ce faisant, elle se rendra insensible à toute manifestation passionnelle et ainsi récure-t-elle, tout en invoquant la raison, son propre avilissement, son déshonneur : abandonnée par ses parents à l'âge de six ans, elle le sera encore par son mari ingrat. Impuissante devant l'autre qui la dégrade et consciente de sa condition de femme à cette époque, elle souhaite, à sa manière, se venger de la société, de la famille, surtout de l'amour. Nous pourrions aller jusqu'à dire qu'elle détourne sa jeune protégée des chemins du cœur et souhaite diriger Pauline, certes pour la protéger dans un premier temps, vers la médiocrité à laquelle elle la destine, en l'occurrence vers Hacqueville, pour en tirer, peut-être inconsciemment ou par calcul, un plaisir à la limite du sadique : sa jeune mantorée ne pourrait réussir où elle-même aurait si lamentablement échoué. Ce serait aussi la victoire de la roturière sur l'aristocrate, ce qui est encore inadmissible en 1747. Le projet d'Eugénie se voudrait aussi d'ordre pédagogique, mais d'une pédagogie dépassée, qui proscrit au lieu d'éclairer, de former l'esprit : cette mère putative veut éviter que son enfant fasse les fautes qu'elle-même a faites et qui lui ont tant coûté. La saugrenuité de cet axiome est attestée par la faillite d'un système éducatif fondé plus sur les anciennes prétentions du pater familias que sur le bonheur de l'enfant. Ce système sera fondamentalement remis en question au XVIII ${ }^{\mathrm{e}}$ siècle, Montesquieu et Jean-Jacques Rousseau en étant sans aucun doute les porte-parole les plus éminents. Cependant, Eugénie demeure très ambiguë à cet égard et le bonheur tel que souhaité par Pauline, bonheur qui est d'ailleurs le but ultime des Lumières, n'est pour la jeune prosélyte qu'une chimère, du plomb dans l'aile, un défi aux lois de l'establishment représentées ici par celles du père, métonymie, du roi et, par gradation, de Dieu même.

\footnotetext{
${ }^{9}$ Blaise Pascal, Pensées (433-277), Cuvres complètes, 1963, p. 552.
} 
Ce faisant, Eugénie rejoint le projet de la mère naturelle de Pauline dont le souci premier est de parvenir à se garantir une place dans la classe noble. C'est dans ce but ambitieux mais essentiel que la mère pousse sa fille à épouser le marquis de N..... ; Eugénie rappelle sa protégée à son devoir de fille obéissante. Tiraillée entre les deux, Pauline est à la fois l'antinomie d'Eugénie et de sa mère, les deux représentant deux signifiants du même signe : l'establishment et ses lois immuables. Pauline finira, cependant, par se réconcilier à la fin de ce roman-mémoire avec son cœur, qu'elle n'avait d'ailleurs jamais démenti : plus proche du « cœur » marivaudien que de la vertu clévienne, dans la solitude de son château, elle refusera sans les dénigrer les précautions et les conseils quelque peu surprenants de son mentor. Les leçons d'Eugénie se révéleront ambiguës, à la limite du déraisonnable, du fanatique et de l'immoral narcissique, tant d'éléments qui définissent et caractérisent une classe noble et décadente à l'époque où écrit Madame de Tencin.

Grâce à Eugénie, Pauline quitte la sphère de l'innocence pour rentrer dans la sphère de l'expérience, ce qui lui révélera certes une réalité troublante et des plus amères, hors de l'enceinte protectrice des tombeaux vivants des cloîtres désormais impossibles à défendre : la jeune Claudine-Alexandrine, n'avait-elle pas dans sa jeunesse aimé mieux les dangers de la société à une vie de récluse, dirigée et manipulée par l'establishment ? À la fin du roman, Pauline trouvera une sorte de paix : elle qui, dans un premier temps, se heurte contre les obstacles d'une destinée tracée par sa mère et ensuite par Eugénie son mentor, opte, sur les traces de Camille (Horace de Corneille), de Roxane (Les Lettres persanes de Montesquieu), de Silvia (Le Jeu de l'amour et du hasard de Marivaux), ou encore de Marianne (La vie de Marianne de Marivaux) ou de Zilia (Les Lettres d'une Péruvienne de Françoise de Graffigny), pour une destinée souhaitée, dont la seule boussole serait celle de l'amour et du cœur. Et, tout compte fait, quand le cœur triomphera au dénouement des Malheurs de l'amour, un dénouement qui ne sera certes pas des plus heureux mais apaisant, il aura déjà laissé derrière lui une suite de malheurs tournés vers un avenir, nous en convenons, assez flou et opaque, néanmoins fondé sur la jeunesse, sur la vie et sur l'espoir. « Je nourrissais ma douleur de l'espérance, » dit Pauline, « que du moins un jour la même terre nous couvrirait tous deux. » Après la mort de son amant, elle renoncera au monde mais soutiendra « cet enfant (l'enfant de Barbasan et d'Hippolyte), que la mort de son père m'avait rendu mille 
fois plus cher, » dit-elle, « et était devenu mon unique bien [...]. J'allais m'enfermer avec ma chère Eugénie : et sans m’engager par des vœux, je renonçais au monde pour jamais. $»^{10}$

À juste titre, nous pourrions nous poser la question à savoir qui est le guide véritable, le mentor dans ce texte. Si à la première lecture du roman Eugénie est investie de ce rôle hautement symbolique, il revient au cœur, à ses raisons cachées et à l'amour le soin de diriger les êtres, un principe plus spirituel que philosophique (toujours selon la perspective pascalienne) et que les années autour de 1730 mettent en vedette grâce surtout à Marivaux. Il revient à celui-ci le mérite d'avoir marqué le passage symbolique de la sphère du paraître (la mondanité) à celle de l'intimité familiale et qui atteindra son paroxysme chez Diderot et le drame bourgeois. Si du point de vue narratologique La Princesse de Clèves reste chez Madame de Tencin le mentor à imiter ${ }^{11}$, sur les traces de Silvia ${ }^{12}$, Pauline saura sortir de la prison existentielle créée par son illustre devancière et ensuite par Eugénie, et donnera un sens à sa vie, un sens qui dépasse le narcissisme de la célèbre princesse : accablée par la peur, par son sens de culpabilité et par l'impossibilité de s'assumer, celle-ci choisit la solution la plus facile, celle de se laisser mourir - elle pense justement à son « repos » intérieur, mais à «l'inconstance » des hommes et de leurs sentiments aussi : Eugénie ensevelie dans son cloître, apparemment par choix, s'épanouira, comme son illustre « sœur» clévienne, dans l'illusion d'avoir obéi à son devoir, sans avoir rien accompli ${ }^{13}$. Ne soyons cependant pas trop dur envers Eugénie et évitons l'anachronisme : la société l'a certes maltraitée, mais elle aurait pu dépasser son cynisme et s'engager - l'auteur de ce roman en est d'ailleurs un des porte-parole les plus remarquables du siècle -, faire la différence et se battre, ne serait-ce que pour une lueur de bonheur, un peu comme Roxane (lettre CLXI, Lettres persanes, de Montesquieu) ou encore comme Zilia (Lettres d'une Péruvienne de Françoise de Graffigny) ou enfin comme le fera plus tard Julie (La Nouvelle Hélö̈se de Rousseau). Justement, à l'abnégation de La Valette, son fidèle amant, qui lui fait entrevoir la possibilité du salut, mademoiselle de Joyeuse (devenue ensuite Eugénie) répond par les signes d'un renoncement total à la vie, ce qui, au XVIII ${ }^{\mathrm{e}}$ siècle n'est plus perçu comme les signes les plus sonores de la révolte contre la tyrannie

\footnotetext{
${ }^{10}$ Les Malheurs de l'amour, op. cit., p. 148-149.

${ }^{11}$ Madame de Lafayette, La Princesse de Clèves, 1966, p. 172-180.

12 Marivaux, Le Jeu de l'amour et du hasard, dans Théâtre complet, 1949, p. 675-725.

13 Patricia Louette remarque chez le personnage d'Eugénie « le triomphe d'un narcissisme agressif, voire sadique, dont Pauline fera aussi les frais (à travers les conseils reçus)». (Texte cité par Andrea Turekova, art. cit. p. 79.)
} 


\section{Sante Viselli}

des hommes, mais plutôt comme une dégradation complète de convention qui sous-tend ce qu'elle reprouve :

Mes malheurs, répliqua mademoiselle de Joyeuse [elle prendra le nom d'Eugénie une fois devenue religieuse], ne m'ont pas laissé le choix de ma destinée ; il faut vivre dans la solitude, puisque je ne saurais plus me montrer dans le monde avec honneur. Eh ! pourquoi, dit M. de La Valette, vous en faire cette cruelle maxime ? Pourquoi vous punir [...] ? Non, poursuivit-il en la regardant de la manière la plus tendre, je ne renoncerai point à des prétentions que votre cœur semble ne pas dédaigner. J'avoue, répliqua mademoiselle de Joyeuse, que si je l'avais écouté, il n'eût parlé que pour vous. Il faut avouer plus, ajouta-telle, ce fut pour me venger de vous, dont je croyais avoir été trompée, que je me précipitai dans l'abîme des malheurs où je suis tombée. Accordez-moi donc, interrompit le marquis de La Valette, la gloire de les réparer. ${ }^{14}$

Le cri de la célèbre princesse ainsi que celui d'Eugénie demeurent impuissants, stériles, entropiques. Où serait donc cette vertu tant célébrée dans tous ces discours y compris celui de la mère de la célèbre princesse ? Les deux romans ne laissent pas de doute dans l'esprit du lecteur/de la lectrice sur l'échec de leurs sermons et de leur éducation. Cependant, il faut renchérir là-dessus, la princesse ainsi qu'Eugénie font partie de l'aristocratie, une classe déjà affaiblie et bientôt condamnée à la disparition : comme c'est le cas pour Adélaïde dans Les Mémoires du comte de Comminge ${ }^{15}$, elles n'assureront à leur famille aucune descendance, tandis que, malgré ses déboires, Pauline réussira à assurer l'avenir à son fils putatif, fruit d'une sensibilité autre, d'une union entre son amant noble et la fille d'un geôlier, un enfant donc de souche à la fois noble et roturière ${ }^{16}$. Ce genre d'alliances exprimées de manière encore timide par Madame de Tencin - Barbasan n'épousera pas Hippolyte -, sera repris par Jean-Jacques Rousseau (La Nouvelle Héloïse) qui suivra le même modèle topique et narratologique - SaintPreux n'épousera pas Julie malgré les efforts de milord Édouard - s'épanouira après la Révolution chez Isabelle de Charrière dans les Lettres trouvées dans des portefeuilles d'émigrés.

\footnotetext{
${ }^{14}$ Idem, p. 120.

${ }^{15}$ Madame de Tencin, Mémoires du comte de Comminge, 1985, p. 94. Le dénouement de ce court roman met en scène la mort de l'héroïne Adélaïde et la retraite du héros dans la solitude d'un lieu écarté où il n'aura «d'autre occupation que celle de pleurer ce [qu'il a) perdu ». Le pathétique de ce dénouement marque bien l'échec de tout un système fondé sur l'autorité d'un père, métonymie et allégorie d'une abstraction qui renvoie le lecteur averti des Lumières à des signifiants devenus désormais des lieux muets : la mise à mort symbolique du père marquée par l'absence de progéniture montre bien que son rôle est devenu inutile. Quelques décennies plus tard, on lui tranchera la tête et ce sera l'avènement d'un monde autre qui fera fi, au moins théoriquement, de l'arbitraire, du fanatisme, du despotisme, de l'ignorance et de la superstition sur lesquels se fondait l'Ancien Régime.

${ }^{16}$ Michel Serres, dans sa remarquable étude intitulée Le Tiers-Instruit (1991) évoque justement l'importance du métissage comme une des conditions de survie de l'humanité en crise. C'est une réponse possible préconisée par Madame de Tencin à cette crise de classes évoquée dans Les Malheurs de l'amour. C'est à ce jeune "métis " qu'appartient l'avenir.
} 
À l'aube d'un renouveau politique social et moral sans précédents, le dénouement de ce court roman qui, à notre avis, reste intentionnellement inachevé, ouvre un soupirail d'optimisme sur une nouvelle aurore, celle inaugurée par l'union de l'aristocrate et du bourgeois révolutionnaire ${ }^{17}$. Ceci est encore inconcevable en 1747, date de parution des Malheurs de l'amour de Madame de Tencin.

Du point de vue sociologique et phénoménologique, le sujet narratologique désigne une voix plurielle : par le truchement de Pauline, la voix de la noblesse continue à dicter ses lois intransigeantes mais, en même temps, cette voix/voie est investie d'un rôle messianique et sera porte-parole de la nouvelle société qui souhaiterait abolir la distance entre les classes. Pauline appartient à la bourgeoisie riche et dynamique, convoitée bien sûr par une noblesse faible et décadente, qui méprise la classe bourgeoise mais qui ne peut cacher les signes de sa propre indigence. Le rôle de la mère de Pauline, sorte d'anti-héroïne dans ce roman, est un exemple assez symptomatique des contradictions qui hantent les deux classes : à la riche bourgeoisie de l'époque il répugne l'état (le Tiers État) dans lequel elle est reléguée, elle veut s'en libérer à tout prix et ce désir narcissique lui sera fatal. Ainsi la bourgeoise, déchirée par son complexe d'infériorité, s'avoue-t-elle indirectement coupable en courtisant et en adulant une noblesse qui la hante mais qui féconde et séduit son imagination ulcérée par le charme d'appartenir à un état qui n'est pas le sien. C'est le complexe d'Icare : comme celui-ci, elle ose défier l'interdit qui lui sera fatal. Pauline n'a plus besoin de parvenir comme sa mère : elle fait déjà partie d'un univers autre, mais elle ne se libère pas de ses aspirations quelque peu romantiques avant la lettre, elle ne se libère non plus de son guide, cause première de sa déchéance.

Fiction romanesque oblige, Pauline tombe amoureuse d'un objet illusoire et Eugénie fera de son mieux pour détourner sa protégée de cette inclination qui révélera dans ce roman un Éros continuellement bafoué par Thanatos. Après la rencontre du jeune et séduisant Barbasan, la narratrice est entrainée dans le vertige de cet amour qui fut préalablement si redoutable à Eugénie et dont cette dernière voulait préserver sa jeune pensionnaire apprentie. En faisant cela, Eugénie l'empêche de vivre. Jeune fille très vulnérable, Pauline à sa sortie du couvent rencontre le monde qui fréquentait la maison de ses parents, jeunes gens vaniteux, babillards ignorants, des petits-

\footnotetext{
${ }^{17}$ Isabelle de Charrière, Lettres trouvées dans des portefeuilles d'émigrés, Paris, Côté-femmes, 1993. Laurent, jeune révolutionnaire appartenant au Tiers-État, tombe amoureux de sa prisonnière, la noble Pauline qui, comme dans la fable, finit par aimer le bourgeois jacobin.
} 
maîtres typiques. Ignorante et complètement détachée de la réalité, toute cette parade sociale ne la touche aucunement et pour s'en consoler, elle cherche refuge entre les bras de son mentor :

J'allais tout conter à mon Eugénie, elle riait de mes dégoûts et de mes surprises. Gardezvous, comme vous êtes, me disait-elle, le plus longtemps que vous le pourrez. Votre père vous aime ; profitez de cette tendresse pour choisir un mari qui vous rende heureuse : votre raison et votre cœur ne parlent encore pour personne; je voudrais bien que le cœur se tût toujours. Mais je crains qu'il ne se mêle un jour de vos affaires plus qu'il ne faudrait. Vous avez un fond de sensibilité qui m'alarme pour le repos de votre vie. Vous êtes perdue, mon enfant, si vous trouvez quelqu'un qui sache aimer, et vous persuader qu'il vous aime ${ }^{18}$.

La liaison avec Barbasan s'avèrera assez décevante, car les deux amants sont vite condamnés au silence et nous en avons esquissé les grandes lignes un peu plus haut. Mais le silence est un grand maître comme le dit le sage et dès la première étape de cette liaison « un trouble agréable, que je n'avais jamais éprouvé », remémore la narratrice, « remplissait mon cœur » (46). Le cœur sera ainsi valorisé dans ce roman et le lecteur assiste à une véritable mise en scène de cette voix univoque : la seconde rencontre des deux amants aura lieu dans le magasin d'un peintre

[...] qui avait des tableaux d'une beauté singulière. Barbasan y était : quoiqu'il y eût assez de monde, $[. .$.$] je crois que je ne vis que lui. Le cœur me battit : j'avais peur qu'il ne sortît ;$ [...] nous étions pleins l'un l'autre de cette douce joie que l'on ressent quand on commence de s'aimer, et que l'on paye ensuite si chèrement. [...] Je n'étais plus si pressée d'aller voir Eugénie : l'amitié devient plus faible quand on commence à être occupé de sentiments plus vifs; et si elle reprend ses droits, ce n'est que lorsque le besoin de la confiance la rend nécessaire $[\ldots]^{19}$.

Suite à cette nouvelle rencontre, Pauline ira voir sa directrice de conscience et lui esquissera un portrait très avantageux de son amant, fera l'éloge de son esprit, de sa sagesse, que des lieux communs du discours amoureux. Devenue sceptique à cause de son expérience personnelle vécue, Eugénie demeure insensible devant l'enthousiasme de sa pupille qu'elle démolit de manière systématique : elle la met en garde contre son cœur et contre les circonstances

\footnotetext{
${ }^{18}$ Les Malheurs de l'amour, 2001, p. 44-45. L'amour et le mariage sont sujets à bien d'autres paramètres au XVIII ${ }^{\mathrm{e}}$ siècle (les lois du père, l'héritage, le droit d'aînesse, le mariage de raison, la séparation des classes sociales, les codes, etc.,) et les discours s'y rapportant sont bien discordants. Ceci n'est pas nouveau, mais le siècle des Lumières reviendra sur la question du cœur, une question plus philosophique que sentimental, car, de ce principe dépend toute une vie. C'est un rappel de la Lettre 116 des Lettres persanes de Montesquieu, mais aussi de la plus célèbre des comédies de Marivaux, ami intime, comme Montesquieu d'ailleurs, de Madame de Tencin. Voir Le Jeu de l'amour et $d u$ hasard, 1949, Acte I, scène 1, p. 678. La réplique suivante de Lisette aux scrupules de Silvia est symptomatique de la réalité de l'époque et du sérieux de la question sur le mariage. SiLviA : «[...] Songe à ce que c'est qu'un mari. » LISETTE : "Un mari ? c'est un mari; vous ne devriez pas finir par ces mots-là ; il me raccommode avec tout le reste. $»$

${ }^{19}$ Les Malheurs de l'amour, 2001, p. 48-49.
} 
souvent trompeuses associées à ces rencontres quelques peu anodines et dont le coup de foudre n'en est que le signe le plus déraisonnable, le plus violent, le plus trompeur, qui entraîne les êtres dans un tourbillon de passions ravageur. Le dénouement ne peut être que catastrophique. La mise en garde assez crue de la maîtresse rusée, accoutumée à lire au delà de l'ambigüité de la parole amoureuse, plonge la jeune amante apprentie dans un état de crainte qui la déstabilise et ne laisse aucune place à l'idée qu'elle se faisait du bonheur souhaité : « il n'y a pas d'amour heureux », dit une chanson bien connue du $\mathrm{XX}^{\mathrm{e}}$ siècle ${ }^{20}$, et les textes littéraires de toute époque semblent donner raison à ce topos du discours amoureux. Le mentor féminin qu'est Eugénie en connaît toutes les ruses : l'amour, le signifié le plus sonore d'une malédiction à bannir, représente le début et la fin de toutes les tragédies, c'est l'épée de Damoclès prête à trancher tout espoir, tout rêve de bonheur. Indirectement Eugénie évoque ici le mythe de Pandore et cet espoir n'est qu'une autre forme de ce mal mythique resserré dans la célèbre boîte et sur lequel repose une société impuissante qui se berce d'illusions et d'optimisme déraisonnable. La pensée est manichéenne et pour triompher du mal, il faudra se débarrasser de la violence de l'espérance, des rêves, en dernière analyse du cœur et de l'amour. Pauline résiste malgré l'ascendant qu'Eugénie exerce sur elle à cette vision du monde, à vrai dire un peu trop cruelle pour une jeune femme de 18 ans, à une réalité qui la révolte mais sous le faix de laquelle elle finira par succomber. C'est ainsi que renchérit Eugénie, véritable serpent dont la sagesse répugne mais convainc. Les circonstances seront toutes en faveur du mentor et contre l'amant potentiellement infidèle :

Il se déguise peut-être mieux, réplique Eugénie au discours laudatif de Pauline. Oh ! pour cela non, répondis-je avec vivacité, je l'ai bien examiné. Pourquoi cet examen, répliqua-telle. Je meurs de peur qu'il ne vous plaise plus qu'il ne faudrait. Prenez garde à vous, mon enfant : quel malheur si vous alliez vous mettre dans la tête un homme que vous ne pouvez épouser, car je conclus, par ce que vous venez de me dire, que ce Barbasan n'est pas dans un rang où l'on vous cherche un mari : gardez vote cœur pour celui à qui vous devez le donner. [...] Quelle triste lumière elle porta dans mon âme ! $!^{21}$

Eugénie prêche donc le conformisme et ce mentor se veut sage dans le sens qu'elle parle $\mathrm{du}$ discours amoureux en connaissance de cause. Ce faisant, elle se fait le porte-parole du statu $q u o$, souhaite prévenir un mal qu'elle associe à son expérience personnelle, enfin elle n'admet pas de bonheur possible dans ce monde et prêche donc la soumission contre toute possibilité de changement. Tout changement souhaité ne pourrait qu'engendrer un mal plus grand que celui

\footnotetext{
${ }^{20}$ Georges Brassens, « Il n’y a pas d'amour heureux », 2001.

${ }^{21}$ Les Malheurs de l'amour, 2001, p. 50.
} 
qu'on aurait voulu éviter : le discours d'Eugénie se fonde sur un mouvement circulaire, obsessif et entropique, c'est le cercle vicieux que seulement la mort pourra briser. Ce mentor ambigu est tout le contraire de l'image du guide qui, grâce à la boussole de la raison - sorte de Virgile dantesque par exemple, ferait sortir sa protégée des horizons bien délimités du savoir acceptable, au-delà de l'enfer du monde, aux lisières d'un bonheur possible. Mais pour cela, Eugénie aurait dû prendre des risques, sortir donc de sa coquille conventuelle et entrevoir un salut souhaité outre l'enceinte du cloître. Eugénie serait-elle déjà le prototype du monstre diderotien, le produit déshumanisé des êtres condamnés à la réclusion? Pauline aurait profité des leçons véritablement philosophiques d'un mentor qui lui aurait montré, avec tous les obstacles à surmonter bien sûr, que la voie du cœur pourrait être le signe le plus sonore qui mène au bonheur. Et le cœur contrarie car son discours se fonde sur la différence et le mouvement, et non sur l'uniformité qui engendrerait plutôt l'indifférence, sur l'engagement, et non sur le protectionnisme des institutions renfermées sur elles-mêmes. «Les instituteurs », dit Michel Serres, « se doutent-ils qu'ils n'ont enseigné, dans un sens plein, que ceux qu'ils ont contrariés, mieux, complétés, ceux qu'ils ont fait traverser? // Certes, je n'ai rien appris que je ne sois parti, ni enseigné autrui sans l'inviter à quitter son nid $»^{22}$. C'est là, selon nous, le véritable mentor porte-parole des aspirations des Lumières.

Madame Élie de Beaumont met en scène le marquis de Roselle, jeune libertin en herbe, tiraillé entre les leçons d'un libertin rusé, Valville, et celles de Madame Saint-Sever (le nom en dit déjà long sur le rôle moral qu'elle a à soutenir dans ce récit), porte-parole de la morale traditionnelle, aristocratique et chrétienne, mais aussi éprise de philosophie rousseauiste, avec une bonne dose de ce sentimentalisme outré si typique de la production larmoyante du siècle des Lumières. Contrairement au texte de Madame de Tencin dominé par le manichéisme, chez Madame Élie de Beaumont le bien l'emporte sur le mal et le roman s'achève sur le retour à l'ordre, à la vertu, au bonheur fondé sur l'amour et sur l'altruisme, et ce grâce au rôle joué par l'héroïne idéalisée, mademoiselle de Ferval. Estimée de madame Saint-Sever (sœur du marquis) et protégée de madame de Narton, mentor de la famille Ferval, mais véritable Deus ex machina dans l'économie du roman, la jeune fille pure, vertueuse et charitable, modèle quelque peu irréel de la perfection féminine à l'époque, réussira à libérer le marquis de ses fantasmes de jeune homme riche et décadent, lui fera apprécier la vie idyllique dans le cadre champêtre où se passe

${ }^{22}$ Michel Serres, Le Tiers-Instruit, 1991, p. 27. 
une bonne partie de cette fiction. Elle deviendra au dénouement la future marquise de Roselle et parviendra ainsi à sortir de sa condition de noble appauvrie, sera choyée par les gens du coin (certes, un rappel émouvant de Julie dans la Nouvelle Héloïse, 1761), et, comble de sa générosité, elle récompensera Léonore, la libertine repentie et responsable de la déchéance initiale du jeune marquis. Chose assez incongrue pour ces chrétiens farouches, c'est grâce au mal initial causé par la libertine que la vertu sera récompensée et le bonheur sera finalement possible, philosophie en principe contestable mais qui rendra compte des effets bénéfiques des causes premières de la chute. Le projet est d'ordre pédagogique et moral et sous-tend le rôle du mentor dans le texte. Monsieur de Ferval, frère de mademoiselle de Ferval, viendra renchérir sur le rôle autocratique de madame de Narton. C'est l'ami fidèle qui se sacrifie pour Roselle, qui sait lui dessiller les yeux au risque de périr par l'épée du marquis aveuglé par la rage de sa passion et par la jalousie : il est l'antithèse de Valville dont le mentorat se réduit à une pédagogie libertine de la vie. Madame Élie de Beaumont raille d'ailleurs dans son roman ce personnage, véritable caricature du libertin. Madame de Narton fait de lui un portrait peu séduisant, mais tout considéré rassurant à ses fins :

Que ce portrait, écrit-elle à son amie, ne vous effraye pas, cet homme pourra nous servir beaucoup. [...] Le vice agit plus adroitement que la vertu; et ses faux préceptes feront une impression plus profonde que vos principes d'honnêteté. Ne doutez pas que Valville, qui s'affiche pour l'ami, pour le Mentor de votre frère, qui l'annonce dans le monde, qui craindroit que le ridicule de cet attachement ne rejaillit sur lui s'il étoit connu, ne se serve de l'ascendant que dix ans de plus et beaucoup d'expérience lui donnent, pour arracher le Marquis aux dangereux liens dans lesquels il l'a lui-même engagééc.

En fait, il revient à Madame Élie de Beaumont le mérite de discréditer le libertinage en le réduisant au simple aspect insignifiant du coureur de jupes ou au rôle du petit-maître oisif : son libertin en pacotille méconnaît la véritable portée d'un Dom Juan, c'est-à-dire un des précurseurs les plus saillants de la philosophie des Lumières, philosophie qui touche à la morale et à la religion bien sûr, mais aussi à la politique et à l'économie de l'époque. De nouveau, à la philosophie d'un bonheur tracé comme le préconisent les mentors féminins chez Madame de Tencin et chez Madame Élie de Beaumont, le libertinage d'un Valville opposerait une philosophie fondée sur le bonheur souhaité, une voie toute personnelle faisant fi de toutes les entraves et responsabilités liées aux préjugés moraux et aux traditions. De ce point de vue, le libertinage semblerait remplir un rôle libérateur et progressif, aux lisières d'un monde plus

${ }^{23}$ Madame Élie de Beaumont, Lettres du marquis de Roselle, 1764, p. 37-38. 
authentique, fondé surtout sur les lois de la nature et sur le plaisir du moi anarchique. Cependant, si cette méthode déconstructionniste semble être valable, Valville est un faible qui se moque de tout, et surtout de son disciple, et qui n'atteindra jamais le statut des libertins de Laclos ou de Sade, grands même dans le mal. Tout compte fait, ce seront les mentors femmes qui l'emporteront d'emblée sur les hommes dans les deux romans considérés dans cette étude. Aussi la silhouette d'un père peu s'en faut absent du discours dans ces deux textes tremble-t-elle devant le changement de sexe du mentor, ce qui renverse toute la structure symbolique du discours classique : n'est-ce pas sous les traits de Mentor que la déesse Athéna s'adresse à ses protégés ? Ainsi la pyramide du pouvoir patriarcal se trouverait-elle irrémédiablement sapée.

Cependant, si Don Juan (dans l'opéra Don Giovanni de Mozart) crie à la veille de la Révolution «Viva la libertà», c'est qu'il souhaite reconquérir une liberté qui n'est plus l'apanage d'une seule classe sociale et d'un sexe : le libertin de Molière comme celui de Mozart est un philosophe, un Prométhée sémiotiquement parlant, épris de soleil, qui souhaite sortir des ténèbres de l'obscurantisme ancestral dans lesquelles baigne une France despotique, bigote et ignorante, soumise à la crainte de l'enfer et à des lois et coutumes désormais désuètes. L'anarchie du libertin ne serait que le cri du désespéré qui grâce à l'hypocrisie, le vice à la mode selon son mot, remonte la pente du désespoir pour s'attaquer à l'Olympe des cuistres d'une France esclave qui aspire après sa liberté. Don Juan aime l'humanité et c'est à ce prix qu'il cherche le feu libérateur. Le libertin de Madame de Beaumont, confronté lui aussi au statu quo sur lequel se fonde l'aristocratie, célèbre plutôt l'anarchie fondée sur un égoïsme aride, entropique. S'il y a du positif dans la philosophie de Valville, c'est de montrer à son jeune prosélyte que l'aristocratie ne peut toujours invoquer le passé comme garant de ses droits : dans un siècle où les prétentions sociales ne suffisent plus, le jeune marquis de Roselle risque de se voir dépassé par les événements qu'il ne comprend pas, son univers d'attente étant celui de l'enfant gâté, protégé outre mesure, dirigé par sa grande sœur et qui refuse de grandir : «Que je voudrais, s'exclame madame de Saint-Séver, faire revenir ce temps heureux, où, dans l'âge de l'innocence, il (Roselle) n'avoit de confiance qu'en moi $»^{24}$. Véritable connaisseuse du cœur humain et beaucoup plus clairvoyante que son amie, madame de Narton la guide et lui conseille une prudence qui dépasse le pathétique de son cri impuissant pour ramener le discours au niveau psychologique et pédagogique :

${ }^{24}$ Lettres du marquis de Roselle, 1764, p. 6. 
Craignez, et ne vous effrayez pas. Il ne faut pas se flatter que votre frere ne donne point dans les erreurs de son âge : tant d'exemples l'y entraîneront! Et c'est en vain que votre sagesse se révolte de tout ce qui n'est pas aussi pur que vous-même: mais il a l'âme honnête, il en reviendra. Vous l'avez jusqu'à présent gardé à vue; il n'est plus enfant, il ne faut pas le traiter comme s'il l'étoit. Observez-le [...]. Votre frere est dans le monde ; c'est pour lui un pays étranger, il doit y être tout étonné. Le premier coup d'œil du monde est enchanteur pour son âge. Il suivra le torrent, [...] il fera des fautes. [...] Lorsqu'une fois on a pris le goût pour les plaisirs et pour le monde, il n'y a que l'expérience qui en désabuse ; les leçons, si elles ne sont adroitement déguisées, n'y peuvent rien ${ }^{25}$.

Du point de vue discursif, cette lettre que madame de Narton adresse à son amie madame de Saint-Sever, sœur du marquis, évoque plusieurs lieux caractéristiques du discours du mentor : les impératifs, sans être des ordres outranciers, invitent à la réflexion, au calme, à la sagesse, à la compréhension et à une sorte d'optimisme pondéré, fondé sur la bonté de la nature humaine. Contrairement à son amie, madame de Narton comprend le monde et ses changements et vit le conflit de générations de manière philosophique, plus attachée à l'être humain qu'aux prétentions qui relèvent d'un discours passé discordant, désormais peuplé de signifiants contradictoires à la limite de l'inintelligible. Par le truchement de madame de Narton, madame Élie de Beaumont invite le lecteur de son roman à ouvrir les yeux sur la réalité, celle de 1764, en pleine Encyclopédie, aux lisières de changements impossibles à ralentir dans un univers en évolution. La valeur de la tradition invoquée par madame de Saint-Sever, sans être tout à fait condamnée, est perçue par le mentor femme comme l'image incongrue d'un univers statique et elle rappelle, de manière très astucieuse, que la tradition n'est aucunement un signe référentiel ni cognitif. Le reste de la lettre s'organise autour de conseils précieux qui renchérissent sur les notions pédagogiques déjà évoquées plus haut :

$\mathrm{Ne}$ vous allarmez point avant le temps; tranquillisez-vous [...]: tâchez de l'attirer [le marquis de Roselle] chez vous; Ils [les jeunes gens] ne peuvent souffrir la dépendance, ni tout ce qui en a l'air [...]. Je crois que vous feriez bien de supprimer les conseils [...] Il [le marquis] ne pourroit s'empêcher de les prendre pour des leçons, et les leçons ne plaisent jamais $[\ldots]$ Pesez-les. Je vous trace la route que je suivrois à votre place $[\ldots]^{26}$.

L'autre discours dans ce roman, celui que le mentor libertin Valville adresse à son prosélyte, est l'antithèse de celui de la dame porte-parole de la morale traditionnelle mais clairvoyante :

Je te croyois un peu plus raisonnable, Marquis ; d'honneur, je le croyois. Tu avois reçu des leçons d'un maître assez habile, tu n'en as pas trop profité.

\footnotetext{
${ }^{25}$ Idem, p. 8-9.

${ }^{26}$ Idem, p. 10-15.
} 
Vous autres grands enfants, vous êtes sujets à prendre vos premières palpitations pour de l'amour. Je prévois qu'il ne sera pas aisé de te corriger de la mauvaise éducation qu'on t'a donnée ${ }^{27}$.

Dans cette fiction romanesque, le libertin ne triomphera pas et le jeune marquis, après une longue période dépressive, sera sauvé par les soins d'autres jeunes héros que madame Élie de Beaumont fera intervenir pour assurer un dénouement heureux à ce récit. C'est peut-être un moment faible du roman et la ligne de force finale risque de s'effondrer sur les écueils du sentimentalisme et de l'utopie fondée sur la perfection et le bonheur retrouvés dans le cadre champêtre et simple, lieu qui permet la naissance et l'éclosion de l'amour véritable. Cette évocation de l'amour possible dans un cadre idéal, s'oppose à la présence du vice (évoqué par Valville), sur lequel se fonde le discours idéal du retour à la campagne versus le discours de la ville, monde souillé et aseptisé, caractérisé par la recherche à outrance du plaisir anarchique.

Un autre exemple de topos déjà repéré par les Satoriens étoffe le dénouement du roman : c'est le topos de la libertine repenti. Rappelons que la libertine (Léonor) réussit à séduire le marquis au point que celui-ci souhaite l'épouser malgré les remontrances de ses guides moraux : sa sœur Madame Saint-Sever et Madame de Narton. Ceci permet à l'auteur de conclure son roman de la manière qu'elle désire : ce sera le triomphe du code moral et des valeurs ancestrales sur lesquelles se fonde le véritable bonheur. C'est ainsi que s'exprime Léonor dans la dernière lettre du roman qu'elle adresse à son ancien amant, le marquis de Roselle :

Voilà, Monsieur, ce que mes remords, ma reconnoissance, la vertu dont vous m'avez frayé la route, voilà tout ce que ces sentiments réunis m'ont forcé de vous déclarer. Jouissez du bonheur pur qui vous a été réservé. Félicitez-vous sans cesse de vous voir arraché à mes dangereux liens, et d'avoir mérité la plus aimable et la plus vertueuse des femmes. Le cœur plein de vos bienfaits et de mes fautes ; si j'ose, après tant de crimes, invoquer le Ciel pour d'autres que pour moi, je ne cesserai de lui demander pour vous, Monsieur, et pour Madame la Marquise de Roselle, ses plus grandes faveurs; et ce sera l'emploi le plus doux du reste d'une vie prête à s'éteindre ${ }^{28}$

Qu'est donc devenu le mentor au siècle des Lumières? Il n'a pas été possible de répondre à cette question dans une étude partielle et partiale comme celle-ci, les deux auteurs femmes et les deux romans choisis ne répondant certes pas à la complexité soulevée par la richesse du topos et par la diversité du roman de l'époque. Ce qui nous a séduit en préparant cette analyse, c'est la

${ }^{27}$ Idem, p. 27-28.

${ }^{28}$ Lettres du Marquis de Roselle, 1764, p. 165. 


\section{Sante Viselli}

présence du mentor femme qui acquiert dans les discours de Madame de Tencin et de Madame Élie de Beaumont une dimension comparable sinon supérieure à celle retenue par le mentor classique et que Fénelon remet à la mode à la fin du XVII ${ }^{\mathrm{e}}$ siècle. Il serait souhaitable de donner suite à ces quelques propos et faire voir que la fiction littéraire de l'Ancien Régime n'oublie pas la présence de ce guide dont la sensibilité autre semble porter en soi tous les aspects de «l'honnête femme ».

Sante A. VISELLI Université de Winnipeg 


\section{Annexe. D'autres exemples de mentor présents dans quelques romans du XVIII ${ }^{\mathrm{e}}$ siècle :}

- Les Lettres persanes. Montesquieu y met en scène un mentorat qui se révèle contradictoire, où Usbek, mentor de Rica, serait lui-même porte-parole du mal qu'il voudrait combattre. Chose assez curieuse, le mentoré semble, dans le cours du roman, dépasser le mentor qui ne réussit pas à se libérer du poids de la tradition, de la religion, de l'ignorance, du despotisme et de tous les préjugés tellement enracinés dans la Perse, métaphore de l'Europe de l'époque. Cependant, Usbek ne part pas pour retrouver la trace du père comme ce fut le cas pour son illustre prédécesseur Télémaque, mais surtout pour acquérir la sagesse et le philosophe persan exprime déjà ce désir dans sa première lettre à son ami Rustan : "Rica et moi sommes peutêtre les premiers, parmi les Persans, que l'envie de savoir ait fait sortir de leur pays, et qui aient renoncé aux douceurs d'une vie tranquille, pour aller chercher la sagesse $»^{29}$. Contrairement à Télémaque, le héros persan échouera lamentablement, il n'aurait défendu que des tombeaux. Rica, cependant, s'engage dans la société, observe, ausculte et, en véritable philosophe, s'émancipe : «Mon cher Usbek, quand je vois des hommes qui rampent sur un atome, c'est-à-dire la terre, qui n'est qu'un point dans l'univers, se proposer directement pour modèles de la Providence, je ne sais comment accorder tant d'extravagance, avec tant de petitesse. ${ }^{30}$ '»

- Candide. Maître de l'antiphrase, Voltaire joue de manière ingénieuse sur le couple maîtredisciple : le rôle du maître se trouve réduit à une caricature du mentor classique. Selon celuici, la sagesse aide le héros à trouver le fil d'Ariane qui lui permettra de sortir du labyrinthe de ses fantasmes, de surmonter les obstacles du « voyage » symbolique pour franchir, grâce à la sagesse acquise après tant de labeur, une autre étape de sa quête, certes non celle du « meilleur des mondes possibles» panglossien, ${ }^{31}$ mais celle qui lui permet d'atteindre un niveau de perception du monde autre, un moment de répit avant de s'embarquer de nouveau. Sans discréditer Mentor, le véritable modèle de Télémaque demeure son père Ulysse, l'éternel insatisfait qui, après tant de péripéties, ressentira cette envie irrépressible qui le pousse à la recherche d'autres expériences. Rappelons au passage ce texte de la Divine comédie de Dante où Ulysse raconte sa dernière aventure : fatigué de cette vie tranquille qu'il avait cependant tant désirée pendant ses vingt années d'absence de chez lui, le héros grec repart pour explorer l'inconnu, ose affronter l'interdit (les colonnes d'Hercule), lance un défi à la mort. Répondant aux vives sollicitations de Dante (toujours accompagné de son mentor Virgile), le héros homérique rappelle la harangue qu'il avait jadis adressée à ses compagnons angoissés : "O frères », dis-je, "qui par cent mille / êtes venus à l'occident, / et à cette veille si petite / de nos sens, qui leur reste seule; / ne refusez pas l'expérience, /en suivant le soleil, du monde inhabité. / Considérez votre semence: / vous ne fûtes pas faits pour vivre comme des bêtes / mais pour suivre vertu et connaissance. " ${ }^{32}$ Candide, jeune héros naïf et inexpérimenté, est à la fois l'anti Télémaque et l'anti Ulysse, obligé de quitter le meilleur des mondes possibles « à grands coups de pied dans le derrière ». Il est bâtard, il n'est donc pas à la recherche de son père, il n'a pas de guide spirituel (un mentor symbolique), Pangloss étant réduit à une formule vide de sens de l'anti discours philosophique des Lumières, formule disséminée un peu partout dans Candide, que tout est pour le mieux, dans le meilleur des mondes possibles. Tous les personnages de ce conte sont des fantoches qu'un dieu

\footnotetext{
${ }^{29}$ Montesquieu, «Lettre première », Lettres persanes, Paris, Gallimard, Folio, 1973, p. 51.

${ }^{30}$ Idem, « Lettre XIX »,p. 156.

31 Voltaire, Candide, Romans et contes, Paris, Garnier-Flammarion,1966, p. 204.

32 Dante, Enfer, Divine comédie, trad. par Jacqueline Risset, Paris, GF Flammarion, 2010, XXVI, 112-120, p. 133.
} 
invisible fait tournoyer dans un monde caricaturé et entropique. Comment en sortir ? Certes pas à l'aide de Pangloss ni de Martin. Les seuls à se sauver de ce carnage littéraire et philosophique, où l'ironie siège en reine, ce sont sans aucun doute Cacambo et la Vieille, personnages qui prouvent sans cesse que la véritable sagesse, celle qui procède de la réalité, l'emporte sur la fable et triomphe même de la satire acerbe de l'auteur. Véritable guide moral, pragmatique et philosophique, la Vieille surtout, sans avoir la baguette magique des fées, sait poser le bon mot et sait agir dans les moments critiques du conte. C'est ainsi, par exemple, que s'exprime la Vieille qui, embarquée avec sa maîtresse pour échapper aux poursuites des autorités portugaises, raconte l'histoire de ses malheurs. Elle souhaite ainsi répondre, sans le pathétique qui accompagne souvent de telles évocations, aux jérémiades de Cunégonde: «Enfin, mademoiselle, j'ai de l'expérience, je connais le monde; donnez-vous un plaisir, engagez chaque passager à vous conter son histoire, et s'il s'en trouve un seul qui n'ait souvent maudit sa vie, qui ne se soit souvent dit à lui-même qu'il était le plus malheureux des hommes, jetez-moi dans la mer la tête la première ${ }^{33} »$.

- Julie ou la nouvelle Héloïse. Jean-Jacques Rousseau revient, dans ce roman, à une vision plus épurée du mentor. Cependant, il y évoque une des problématiques chères aux Lumières, celle des revendications sociales, où les questions de philosophie éclairée s'alternent avec des prises de positions davantage progressistes, à l'aube de changements souhaités pour le bien de l'humanité. Certes, la sagesse, qui semble diriger dans ce roman les discours éclairés des héros principaux, révèle plutôt le côté hideux de la vérité sociale de l'époque érigée en système, et elle échoue lamentablement devant cette mort qui guette et plane sur Julie et, par conséquent, sape tous les rêves de réforme de la société. La petite utopie de Clarens, dans l'intimité du couple Wolmar, tend à faire oublier cet aspect quelque peu controversé du roman dans lequel Saint-Preux, personnage d'ailleurs faible et assez insignifiant, se trouve valorisé malgré lui par Milord Édouard, maître, guide moral et père putatif du jeune héros. Ce guide est cependant cet autre qui vient d'ailleurs, l'Anglais éclairé, plus tolérant et moins attaché aux préjugés de classe que l'on retrouve en France à l'époque où écrit Jean-Jacques Rousseau. Claire parle de lui en ces termes dans la lettre LXII (Première partie) qu'elle adresse à sa cousine Julie :

[...] Édouard avait osé proposer ton mariage avec ton ami (Saint-Preux), qu'il appelait hautement le sien, et auquel il offrait de faire en cette qualité un établissement convenable. Ton père avait rejeté avec mépris cette proposition, et c'était là-dessus que les propos commençaient à s'échauffer. "Sachez, lui disait milord, malgré vos préjugés, qu'il est de tous les hommes le plus digne d'elle et peut-être le plus propre à la rendre heureuse. Tous les dons qui ne dépendent pas des hommes, il les a reçus de la nature, et il y a ajouté tous les talents qui ont dépendu de lui. Il est jeune, grand, bien fait, robuste, adroit; il a de l'éducation, du sens, des mœurs, du courage ; il a l'esprit orné, l'âme saine ; que lui manquet-il donc pour mériter votre aveu ? La fortune ? Il l'aura. Le tiers de mon bien suffit pour en faire le plus riche particulier du pays de Vaud, j'en donnerai s'il le faut jusqu'à la moitié. La noblesse ? Vaine prérogative dans un pays où elle est plus nuisible qu'utile. [...] En un mot, si vous préférez la raison au préjugé, et vous aimez mieux votre fille que vos titres, c'est à lui que vous la donnerez $» .^{34}$

\footnotetext{
${ }^{33}$ Voltaire, Candide, 1966, p. 214.

${ }^{34}$ Jean-Jacques Rousseau, Julie ou la Nouvelles Héloïse, 1967, p. 113.
} 
Cependant, comparable à tous les mentors du siècle des Lumières, milord Édouard n'est pas sans défauts. Immodéré dans la consommation du vin, il tient des propos désobligeants envers son jeune ami. Ayant de justesse évité la honte de se battre en duel contre lui rappelons au passage que Saint-Preux fait partie du Tiers État -, sa sagesse prévaut sur son orgueil, il finira par reconnaître ses torts, lui demandera pardon et deviendra son protecteur. Rappelons aussi que milord Édouard avait lui-même fait l'amère expérience d'une vie marquée par la passion et la déception amoureuse, ce qui peut fausser le jugement du lecteur sur le rôle idéal qui remplit ici l'honnête homme dont la supériorité devrait être à toute épreuve, d'un lecteur d'ailleurs encore farouchement attaché à une vision trop noble du mentor mythique, mais prévenu aussi envers un Jean-Jacques Rousseau à une époque où le célèbre homme de cœur se voyait pas mal malmené par l'arrogance d'un Voltaire vindicatif. Il s'agit encore une fois ici d'un mentor tout à fait humanisé, séduisant et séduit, captivé par cet autre - le jeune bourgeois - nouvel espoir d'une société galvanisée par des pressentiments de changements imminents. Contrairement au père de Julie, l'avenir sera, pour ce philosophe anglais, l'apanage de ce que Michel Serres n'hésitera pas à appeler « le tiers-instruit ${ }^{35}$. Et le philosophe anglais n'hésite pas à admettre que tout en guidant son apprenti, il apprend luimême à se conduire, à s'affranchir de ses préjugés, à se rendre maître de ses passions. Dans la lettre XII ( $\mathrm{V}^{\mathrm{e}}$ partie) à $\mathrm{M}$. de Wolmar, Saint-Preux demande conseil à ce dernier : les rôles sont, à cet endroit du roman, renversés car le mentoré devenu mentor s'oppose au mariage « honteux » que son maître et ami souhaite contracter à Rome.

Il s'égare, ô Wolmar ! je le vois, je le sens ; [...]. Je frémis en songeant jusqu'où son égarement peut lui faire oublier ce qu'il est et ce qu'il se doit. Je tremble que cet intrépide amour de la vertu, qui lui fait mépriser l'opinion publique, ne le porte à l'autre extrémité et ne lui fasse braver encore les lois sacrées de la décence et de l'honnêteté. Edouard Bomston faire un tel mariage !... vous concevez !... sous les yeux de son ami !... et qui lui doit tout ! [...].

Cependant que faire? Comment me comporter? Vous connaissez sa violence... On ne gagne rien avec lui par les discours, et les siens depuis quelque temps ne sont pas propres à calmer mes craintes $^{36}$.

Il n'empêche que, malgré ces évocations discordantes par rapport à milord Édouard, ce dernier est l'exemplum du mentor des Lumières, celui qui est, avant tout, caractérisé par des qualités humaines, son approche étant plus anthropologique que morale, plus proche des revendications des Lumières que des mœurs préconisées par l'aristocratie et faussement autorisées par la religion d'État. L'on pourrait appliquer à milord Édouard cette célèbre réplique de Don Juan qui, aux lisières de cette forêt symbolique où il vient de s'égarer, rencontre le Pauvre : celui-ci lui demande au nom du «Ciel » l'aumône. D'un ton hautain et provocateur, le héros de Molière lui répond en lui lançant un louis d'or : « Va, va, je te le donne pour l'amour de l'humanité » ${ }^{37}$.

Dans les Euvres érotiques en général et dans l'Éducation de Laure en particulier, Mirabeau met en scène un mentor qui va tout à fait à contre-courant par rapport à ces moralistes porte-parole de traditions désuètes ou à la limite contestées : le mentor, le père de Laure, est un libertin qui sape les fondements d'une société dont la morale fondée sur des contraintes arbitraires se verrait, au nom du droit naturel dont devrait jouir tout être d'atteindre le bonheur, libérée de la crainte, de

\footnotetext{
${ }^{35}$ Michel Serres, Le Tiers-instruit, Paris, Éditions François Bourin, 1991.

$36{ }^{36}$ Jean-Jacques Rousseau, Julie ou la Nouvelles Héloïse, 1967, p. 472.

${ }^{37}$ Molière, Dom Juan, Paris, Petits classiques Larousse, 1998, Acte III, scène 2, p. 96.
} 
l'ignorance, du fanatisme et du despotisme sur lesquels repose le pouvoir politique et moral. À la base de la pensée de ce mentor, qui pourrait à plusieurs égards être quelque peu choquante, c'est le principe de la philosophie hippocratique "primun non nocere », c'est-à-dire que toute action est moralement licite pour jouir ou soulager la souffrance pourvu que les actes ne nuisent ni à l'individu ni à la stabilité de la société38. Dans les Euvres érotiques de Mirabeau, le mentor rappelle l'existence de cette ligne de démarcation - ce sont les notions d'otium et de negotium déjà si chères aux Romains - entre la sphère du privé et celle du public. Dans la sphère du privé, les êtres peuvent se « déshabiller », se montrer dans toute leur nudité naturelle ; dans cet état de nature leurs actions ne nuisent à personne $:^{39}$ ils sont véritablement libres et à l'aise tandis que, dans la sphère publique, tout comportement doit être réglé. La société, qui est un corps artificiel " cultivé », impose l'habit du paraitre selon les normes établies, parce que le salut de l'individu est subordonné à celui de la communauté. La question n'est plus seulement d'ordre moral, mais politique et pragmatique: dans la sphère du «cum», il «faut remettre le masque de l'hypocrisie $\gg{ }^{40}$. Mirabeau évite de justesse l'inceste dans les Euvres érotiques, mais ce topos est en général une constante du roman libertin de l'époque : "Non, non, » dit le prétendu père à Laure, " apprends de bonne heure à réfléchir et à former ton jugement, en le dégageant des entraves du préjugé, dont le retour journalier t'obligera sans cesse d'aplatir le sillon qu'il tâchera de se tracer dans ton imagination $\rangle^{41}$. La libération intellectuelle de Laure pourra seulement se faire grâce à une libération physique ${ }^{42}$. Ajoutons à cet exemple de Mirabeau, les exemples bien répertoriés de Laclos ou de Sade, mais aussi les moins connus comme Thérèse philosophe de Boyer d'Argens, ou Lolotte de Nerciat parmi d'autres.

Dans les Lettres trouvées dans des portefeuilles d'émigrés, Isabelle de Charrière fait parler un prêtre réfractaire, l'Abbé Des***. Le rôle que remplit ce mentor pendant la période

\footnotetext{
${ }^{38}$ Mirabeau, Euvres érotiques, Intr. Charles Hirsch, Paris, Fayard, 1984, pp. 9-18.

${ }^{39}$ Cette idée est assez commune chez les philosophes depuis Montaigne, qui étudient les principes qui régissent les sociétés réglées, d'où la différence entre le «moi » social et le «moi » individuel. Le discours acquiert au XVIII $\mathrm{e}$. une dimension plus anthropologique et essaye de concilier l'idée de nature et celle de «civilisation». Voir, entre autres, Le Baron den Lahontan, et Jean Jacques Rousseau qui soulignent les rapports entre l'habit et la parade sociale. Mirabeau montre cette idée à plusieurs reprises dans Les CEuvres érotiques. Dans L'Abbé Il-et-elle, p. 226, l'écrivain libertin décrit une scène où les personnages sont peints « dans l'état où nos premiers parents étaient dans l'Éden avant que la pomme fatale leur eût appris qu'ils étaient sans vêtements. »

${ }^{40}$ Mirabeau dans L'Abbé Il-et-elle et ensuite dans L'Éducation de Laure ou le Rideau levé, revient sur cette idée clé qui fait le rapport entre le naturel et l'artificiel de nos relations humaines: Monseigneur l'évêque, un des personnages de ce conte, renchérit ainsi à ce sujet : «Qu'importe à la société que je satisfasse mes besoins physiques ou que je m'en prive, pourvu que ne nuise pas au bonheur d'autrui, que je ne lui enlève pas sa propriété, que je n'altère pas ses jouissances et que ne lui cause ni chagrin ni douleur? [...] Laure a dix-sept ans et n'ignore pas sûrement la différence de son sexe et du nôtre ; mais les détails lui sont peut-être inconnus, nous nous gênons pour elle, nous affligeons sa curiosité, et peut-être, en nous quittant, fera-t-elle des questions à sa femme de chambre qui, moins discrète et moins éclairée, en lui faisant le tableau des plaisirs ne lui en peindra pas les dangers. [...] Quand elle verra que nous ne lui cachons rien, elle sera sans dissimulation, nous lirons dans son âme et nous pourrons écarter d'elle les dangers sans en éloigner les plaisirs. [...] Plus de gêne devant elle tant que nous n'aurons pas d'étrangers ; quand il en viendra de suspects, remettons le masque de la réserve » (L'Abbé Il-et-Elle, p. 242-245). Dans L'Éducation de Laure, la jeune initiée à l'art d'aimer écrit ceci à Eugénie : « Ainsi, ma chère Eugénie, il ne faut choquer personne ; gardons nos confidences libertines pour nous égayer dans le particulier; c'est à toi seule que je veux ouvrir mon cœur ; c'est uniquement pour toi que je ne couvrirai d'aucune gaze les tableaux que je mettrai sous tes yeux. Ils seront cachés pour les autres, ainsi que les libertés que nous avons prises ensemble » (p. 315).

${ }^{41}$ Mirabeau, L'Éducation de Laure dans Euvres érotiques, p. 319.

${ }^{42}$ S. A. VISELLI, "Libération intellectuelle et libération sexuelle chez Mirabeau ». Proceedings of the Linguistic Circle of Manitoba and North Dakota, 1988, Vol. 28, $42-44$.
} 
révolutionnaire est d'ordre politique et il s'exprime de manière avisée sur les causes et les effets de la Révolution. Il communique ses pensées à son prosélyte Alfonse, jeune aristocrate qui, sans adopter tout à fait le nouveau catéchisme révolutionnaire, ne le condamne pas non plus. Alfonse veut avant tout comprendre et essaye d'envisager la nouvelle réalité qui s'impose à la société française et à l'Europe de cette fin du XVIII ${ }^{\mathrm{e}}$ siècle de manière éclairée, plus sage et pertinente que la politique de la Contre-Révolution qui rejette le nouvel équilibre de forces souhaité après 1789. En cela, le mentor et son disciple s'opposent au Marquis de***, porte-parole impassible du statu quo moral, social et politique préconisé par les partisans de l'Ancien Régime : "votre cher Alfonse marche sur vos traces », reprochera-il au prêtre réfractaire (p. 60) ${ }^{43}$. Le roman se clôt sur l'espoir d'un nouvel univers souhaitable versus un univers statique tracé par tant de siècles d'immobilisme moral et politique. Cependant, Isabelle de Charrière ne donne pas de dénouement à son texte : c'est un exemplum d'œuvre ouverte telle que préconisée par Umberto Eco à la fin du $\mathrm{XX}^{\mathrm{e}}$ siècle ${ }^{44}$.

Enfin, dans L'Émigré, Sénac de Meilhan met en scène ce remarquable personnage, le Président de Longueil, véritable mentor et protecteur à tous les égards du marquis de Saint Alban, le personnage principal du roman. Le Président est parmi tous les mentors du siècle des Lumières celui qui se rapproche le plus du mentor classique : il est intelligent, clairvoyant et désintéressé, moralement intègre, honnête homme et accompli. Conscient du grand dérangement qui vient de secouer son pays et le monde occidental et, en être rationnel et lucide, il sait peindre de manière éclairée et intelligente la nouvelle réalité politique, sociale et morale européenne engendrée par la Révolution (voir Sénac, lettre LXXV, p. 233-235). Il sait enfin diriger moralement et philosophiquement son mentoré et demeure pour le jeune marquis le père putatif, estimé, aimé, sa boussole symbolique dans le labyrinthe existentiel des signes contradictoires de l'après $1789^{45}$. C'est ainsi que s'exprime le marquis de Saint Alban dans la lettre LXXXII au Président de Longueil :

Vous ignorez, Monsieur, que vous êtes l'oracle d'une société que vous ne connaissez pas ; j'ai souvent cité vos jugements sur les affaires de la France, j'ai rapporté de vous quelquesuns de ces mots qui décèlent la profondeur du génie, on en a été frappé, et dès qu'il s'agit de conjecturer sur les événements, de résoudre quelque question importante, j'entends dire aussitôt : je voudrais bien savoir ce qu'en pense le Président ${ }^{46}$.

Le Président est le véritable maître à penser du héros de ce roman. À cette fin, nous renvoyons le lecteur à la remarquable lettre LXXXVI où le philosophe fait le bilan de sa bibliothèque que désormais « la nation a mise en vente. » Il conclut cette lettre par une moralité plus sacrée que philosophique que « [...] rien n'est durable dans le monde, et que les pensées et l'estime des hommes sont comme les flots de la mer qui se succèdent et disparaissent $\gg{ }^{47}$.

Ce ne sont là que quelques exemples qui mettent en scène la topique mentor-mentoré et ses tropes selon l'angle de l'analyse topique souhaité par la SATOR. Cette liste n'a aucunement

\footnotetext{
${ }^{43}$ Isabelle de Charrière, Lettres trouvées dans des portefeuilles d'émigrés, p. 60.

${ }^{44}$ Umberto Eco, L'Euvre ouverte, Paris, Seuil, 1965.

${ }^{45}$ S. A. Viselli , «Sénac de Meilhan: Révolution, masque et utopie - quelques considérations à l'aube de l'Europe unie », Dalhousie French Studies, vol. 28, Automne 1994, 43-54.

${ }^{46}$ Sénac de Meilhan, L'Émigré, 2004, p. 243.

${ }^{47}$ Idem, p. 255-268.
} 


\section{Sante Viselli}

prétention à l'exhaustivité, mais se veut un court témoignage de l'ampleur du thème et le souhait d'autres études à venir. 


\section{BIBLIOGRAPHIE}

BEAUMONT, Madame Élie de, Lettres du marquis de Roselle. Londres et Paris, Chez Louis Cellot Imprimeur - libraire, 1764.

BRASSENS, Georges, Coffret Brassens, Les Amoureux des bancs publics, 2, Philips, 2001.

CHARRIÈRE, Isabelle de. Lettres trouvées dans des portefeuilles d'émigrés (1793), Paris, Côtéfemmes, 1993.

DANTE, Alighieri, Enfer dans Divine comédie, Paris, GF Flammarion, 2010. [Jacqueline Risset (trad.)]

LAFAYETTE, Madame de, La princesse de Clèves, Paris, Flammarion, 1966. [Antoine Adam (éd.)]

MARIVAUX, Le Jeu de l'amour et du hasard, dans Théâtre complet, Paris, Gallimard, Bibliothèque de la Pléiade, 1949, p. 675-725. [Marcel Arland (éd.)]

MEILHAN, Sénac de, L’Émigré, Paris, Folio classique, 2004. [Michel Delon (éd.)]

MIRABEAU, Euvres érotiques, Paris, Fayard, 1984.

MOLIÈRE, Dom Juan, Paris, Petits classiques Larousse, 1998.

MONTESQUIEU, Lettres persanes, Paris, Gallimard, 1973. [Jean Starobinski (préf.)]

MORTIER, Roland, Clartés et ombres du siècle des Lumières : études sur le XVIIIe siècle littéraire, Genève, 1969.

PASCAL, Blaise, Pensées dans Euvres complètes, Paris, Seuil, 1963. [Louis Lafuma (éd.)]

SERRES, Michel, Le Tiers-Instruit, Paris, Gallimard, 1992.

TENCIN, Madame de, Mémoires du comte de Comminge, Paris, Desjonquères, 1985.

Les Malheurs de l'amour (1747), Paris, Desjonquères, 2001. [Erik Leborgne (éd.)]

TUREKOVA, Andrea, " Les 'sœurs' de La Princesse de Clèves au XVIII ${ }^{\mathrm{e}}$ siècle : exemple des héroïnes de madame de Tencin », Romanica Olomucensia 25.1, 2013, p. 73-82.

VISELLI, Sante A., « Sénac de Meilhan : Révolution, masque et utopie -quelques considérations à l'aube de l'Europe unie », Dalhousie French Studies, vol. 28, Automne 1994, p. 43-54.

------------ " Libération intellectuelle et libération sexuelle chez Mirabeau », Proceedings of the Linguistic Circle of Manitoba and North Dakota, 1988, Vol. 28, p. 42-44.

« Intertexte et fiction narrative chez Madame de Tencin », Intertexto y Polifonía, Homenaje a Ma Aurora Aragón / coord. por Flor María Bango de La Campa, Antonio Niembro Prieto, Emma Alvarez Prendes, Vol. 1, 2008, p. 715-722. 


\section{Sante Viselli}

« Les Lettres du marquis de Roselle de Mme Élie de Beaumont et l'esprit des Lumières », Dix ans de recherche sur les femmes écrivains de l'Ancien Régime : influences et confluences. Mélanges offerts à Hannah Fournier, Textes réunis par Guy Poirier. Québec :

Presses Université Laval, 2008, p. 233-251.

VOLTAIRE, Candide, dans Romans et contes, Paris, Garnier-Flammarion, 1966, p. 179-259. [René Pommeau (dir.)] 